\title{
Sense of coherence and attrition during four-year follow-up in cohorts of permanent and non-permanent Finnish employees Virpi Liukkonen*1, Pekka Virtanen ${ }^{1}$, Mika Kivimäki ${ }^{2}$, Jaana Pentti ${ }^{3}$ and Jussi Vahtera ${ }^{3}$
}

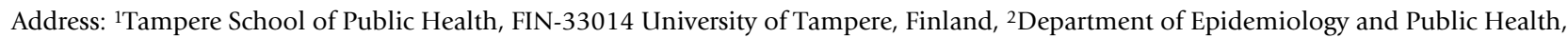
University College London, 1-19 Torrington Place, London, WC1E 6BT, UK and ${ }^{3}$ Finnish Institute of Occupational Health, Hämeenkatu 10, FIN20500 Turku, Finland

Email: Virpi Liukkonen* - virpi.liukkonen@uta.fi; Pekka Virtanen - pekka.j.virtanen@uta.fi; Mika Kivimäki - mika.kivimaki@ttl.fi; Jaana Pentti - jaana.pentti@ttl.fi; Jussi Vahtera - jussi.vahtera@ttl.fi

* Corresponding author

Published: 13 March 2008

BMC Public Health 2008, 8:88 doi:10.1 I86/147/-2458-8-88
Received: 15 June 2007

Accepted: 13 March 2008

This article is available from: http://www.biomedcentral.com/I47I-2458/8/88

(c) 2008 Liukkonen et al; licensee BioMed Central Ltd.

This is an Open Access article distributed under the terms of the Creative Commons Attribution License (http://creativecommons.org/licenses/by/2.0), which permits unrestricted use, distribution, and reproduction in any medium, provided the original work is properly cited.

\begin{abstract}
Background: We studied whether health resources, measured as sense of coherence (SOC), are associated with participation in a follow-up survey among permanent and non-permanent employees who responded at baseline.

Methods: Of a cohort of 5,98I permanent employees, those who after four years were still in the service of the same employer were asked to participate in a follow-up survey. Another cohort consisted of 2,194 fixed-term and 682 subsidised employees; among these the follow-up survey was posted to those whose addresses were found in the population register. Non-participation was divided into loss to follow-up (i.e., failure to locate the individual, death and, among permanent employees, turnover or exit from labour market) and non-response to the follow-up survey. Logistic regression analyses were used to examine whether the respondents differed from the nonrespondents with respect to $S O C$ and other characteristics at baseline.
\end{abstract}

Results: Among permanent employees the follow-up survey yielded 3,998 respondents, I,05I were lost, and 932 did not reply. Among non-permanent employees the follow-up survey yielded I,563 respondents on initially fixed-term and 467 on subsidised contracts, the corresponding figures for those lost were I45 and 38, and for the non-respondents 486 and I77. Low SOC was associated with lower response rate among fixed-term but not among permanent or subsidised employees. No association was found between SOC and loss to follow-up.

Conclusion: SOC is a potential source of non-random sample attrition and should be taken into account for when estimating bias due to non-participation in occupational cohorts that include fixed-term employees.

\section{Background}

The epidemiological knowledge of work-related risks is based mostly on follow-up studies of occupational cohorts in particular workplaces. Such studies are becoming more complicated, as the instability of work life is increasing due to increasing proportions of various tem- 
porary job contracts and higher employee turnover between organisations and occupations. In addition to focusing on the cohort that remains in stable employment during the follow up, epidemiological studies should also trace those employees who left their workplaces, and control for bias related to such attrition.

Sample attrition and the accompanying bias impair the interpretation of the results of health surveys. The reasons for attrition are, in addition to refusal to participate, death or severe illness and failure to locate the individuals. Distinguishing those who cannot be contacted is important, because the mechanism of non-participation may influence the nature of the attrition bias [1-3]. In a cohort study within a workplace or organisation one notable reason for attrition is turnover of workers, which includes many subcategories (e.g. transfer to other workplaces, layoffs and outsourcings, retirement). Instead, in a study of the cohort also including employees who leave the organisation, difficulties in finding individuals' place of residence and address are important reason for attrition.

To the best of our knowledge, only a few longitudinal population-based studies have taken into account sample attrition related to the working situation. The employed tend to participate more actively than unemployed $[1,4,5]$. Badawi et al. [6] found that the unemployed were more difficult to trace and died more often, but unemployment did not influence refusal to participate. The traditional dichotomy of unemployed versus employed, however, is too crude for assessing the modern labour market, where employees may occupy several statuses between permanent jobs and overt unemployment. For example, there is no research among fixed-term employees.

The existing research on the determinants of attrition focuses on sociodemographic factors and health, including mental disorders, but psychological characteristics that may also predict sample attrition are rarely included in these studies. We were interested in the sense of coherence (SOC) $[7,8]$, as a possible source of bias in a cohort study. According to Antonovsky's theory of SOC, a person with strong SOC stays healthy despite possible stressful encounters and a number of empirical studies show that strong SOC is indeed associated with various aspects of good health [9-13]. SOC-related non-response might be hypothesised to be as a potential source of bias in healthrelated survey studies, but there is no research available on a possible association of SOC with attrition or participation.

The aim of this study was to examine sample attrition in a four-year follow-up study among cohorts with initially permanent and non-permanent employment status. We examined baseline characteristics between employees who participated in a follow-up study compared with those who did not. Non-participation was categorised into drop-out due to loss and drop-out due to refusal. Our particular aim was to investigate SOC as a possible source of bias, i.e. we asked whether low SOC predicts refusal to participate in a follow-up survey or exit from the work place or disappearance from the population register. Moreover, we aimed to investigate the associations of participation with sociodemographic characteristics and health in the cohorts of permanent and non-permanent employees.

\section{Methods \\ Participants}

This study was carried out in eight Finnish towns involved in two cohort studies, the 10-Town Study and the Temporaries in Municipal Jobs Study (TMJ Study), both investigating the relationships between behavioural and psychosocial factors and health among municipal employees. The ethics committee of the Finnish Institute of Occupational Health approved the study.

In 1997 the 10-Town Study distributed the initial questionnaire to the workplaces of the participants - full-time employees who were employed by the town. In the small towns the entire municipal personnel was included in the study, while in the three largest towns, a random sample from each town was used. A total of 6,442 employees replied to the initial survey, giving a response rate of $67 \%$. After exclusion of respondents found to be on a non-permanent contract $(\mathrm{n}=461)$, the sample included 5,981 permanent employees. Those who were still employed in the initial municipality were asked to participate in a follow-up survey in 2001.

The TMJ Study was carried out among all employees of the same towns who had a non-permanent job contract in November 1997. This survey (with a response rate of $57 \%$ ) yielded 2,194 participants who reported having a fixed-term contract (i.e. their contract expired at a predetermined point in time because of substitution or "for some other reason"), and 682 subsidised employees (i.e. men and women who had been unemployed for more than 12 months and who were now on a 6 to10-month work contract funded through a government programme to support and enhance the working ability of the longterm unemployed). The follow-up survey was posted in 2002 to all those whose addresses were found in the Finnish Population Register.

\section{Sense of coherence}

SOC was assessed using the 13-item version of the Orientation to Life Questionnaire devised by Antonovsky $[8,14]$. The questions ask the respondents to check their 
level of agreement with items on a seven-point semantic differential scale with two anchoring phrases. In the analysis the respondents were divided into three groups (the highest quartile, the two middle quartiles, the lowest quartile) on the basis of their mean SOC.

\section{Demographic variables and health at baseline}

Data on the respondents' occupations were derived from employers' records, and four categories were defined on the basis of the International Standard Classification of Occupations [15]: professionals (ISCO titles 1-2), associate professionals (title 3), clerks (title 4) and manual workers (titles 5-9). Age was categorised into three groups: 17 to 29 -year-olds, 30 to 49 -year-olds and 50 to 64-year-olds.

Self-rated health was the respondents' overall assessment of their health and was measured with a single question offering five options and dichotomised into good (excellent or fairly good) and poor (average, fairly poor or poor).

\section{Statistical analysis}

We carried out logistic regression analyses to obtain the odds ratios and their 95 percent confidence intervals that reflected the associations between the SOC, demographic characteristics and self-rated health and the two types of attrition. The analyses were adjusted for age, sex, occupational status and baseline level of self-rated health. The respondents of the follow-up survey served as the comparison category. SPSS for Windows version 13.0 statistical software was used in the analyses.

\section{Results}

\section{The cohort of permanent employees}

Among the participants of the baseline survey, 76 per cent of the permanent employees were women, the mean age was 45 years, and 33 per cent reported poor self-rated health (Table 1). The follow-up survey was distributed to 4,930 ( 82 per cent of the baseline participants). The baseline respondents who were not eligible at follow-up ( $\mathrm{n}=$ $1,051,18$ per cent of the baseline participants) consisted of those who had died or had retired because of age or illness and those who had moved to another workplace. The follow-up survey yielded 3,998 respondents (response rate 81 per cent) while 932 employees refused to participate.

Exit from the follow-up cohort of permanent employees did not depend on SOC (Table 1). Exit was most probable in the youngest and in the professionals. Poor self-rated health also predicted exit.

Table I: Characteristics of permanent employees who responded in the baseline and follow-up surveys and who did not respond in the follow-up survey, and odds ratios and $95 \%$ confidence intervals for response at follow-up by characteristic.

\begin{tabular}{|c|c|c|c|c|c|c|}
\hline & \multirow{3}{*}{$\begin{array}{l}\text { Participants of baseline survey } \\
\qquad \begin{array}{c}n=5981 \\
(\%)\end{array}\end{array}$} & \multirow{3}{*}{$\begin{array}{l}\text { Respondents of follow-up } \\
\text { survey } \mathrm{n}=3998 \\
\text { (\%) }\end{array}$} & \multicolumn{4}{|c|}{ Non-respondents to follow-up survey } \\
\hline & & & \multicolumn{2}{|r|}{$\operatorname{Lost}^{\mathrm{a}}(\mathrm{n}=105 \mathrm{I})$} & \multicolumn{2}{|c|}{ Refused $(n=932)$} \\
\hline & & & (\%) & OR $(95 \% \mathrm{Cl})^{\mathrm{b}}$ & $(\%)$ & OR $(95 \% \mathrm{Cl})^{\mathrm{b}}$ \\
\hline \multicolumn{7}{|l|}{ Sense of coherence } \\
\hline High & 23 & 23 & 23 & 1 & 23 & 1 \\
\hline Intermediate & 52 & 52 & 50 & $1.02(0.85-1.22)$ & 50 & $1.08(0.89-1.30)$ \\
\hline Low & 25 & 25 & 27 & $0.94(0.76-1.16)$ & 27 & $0.99(0.79-1.23)$ \\
\hline \multicolumn{7}{|l|}{ Gender } \\
\hline Men & 24 & 22 & 22 & 1 & 33 & $\mathrm{I}$ \\
\hline Women & 76 & 78 & 78 & $0.84(0.70-1.01)$ & 67 & $1.58(1.34-1.86)$ \\
\hline \multicolumn{7}{|l|}{ Age group } \\
\hline $17-29$ & 3 & 2 & 6 & 1 & 5 & 1 \\
\hline $30-49$ & 62 & 66 & 41 & $5.45(3.81-7.78)$ & 66 & $2.23(1.50-3.31)$ \\
\hline $50-64$ & 35 & 32 & 53 & $2.15(1.50-3.08)$ & 29 & 2.51 (1.67-3.78) \\
\hline \multicolumn{7}{|l|}{ Occupational status } \\
\hline Professionals & 38 & 37 & 44 & I & 36 & 1 \\
\hline Associate professionals & 21 & 23 & 17 & $1.69(1.38-2.07)$ & 18 & $1.25(1.01-1.54)$ \\
\hline Clerks & 9 & 10 & 8 & 1.54 (1.18-2.02) & 7 & $1.27(0.94-\mid .7 I)$ \\
\hline Manual workers & 32 & 30 & 31 & $1.37(1.15-1.63)$ & 39 & $0.79(0.66-0.94)$ \\
\hline \multicolumn{7}{|l|}{ Self-rated health } \\
\hline Good & 67 & 70 & 59 & I & 66 & 1 \\
\hline Poor & 33 & 30 & 41 & $0.66(0.56-0.77)$ & 34 & $0.82(0.69-0.96)$ \\
\hline
\end{tabular}

a Employees no longer were in the service of the same employer as at baseline

${ }^{b}$ Adjusted for age, sex, occupational status and baseline level of self-rated health 
Non-response at follow-up was not associated with SOC (Table 1). Participation was less likely among men, in the youngest and in the manual workers. Moreover, nonrespondents had more likely poor self-rated health.

\section{The cohort of fixed-term and subsidised employees}

At baseline, 82 per cent of the fixed-term employees were women, the mean age was 35 years, and 17 per cent reported poor self-rated health (Table 2). The corresponding figures for the subsidised employees were 77 per cent, 38 years and 31 per cent (Table 3 ). The proportion of manual jobs was higher among the subsidised employees than in other employment types.

The follow-up survey was posted to 2,049 (93 per cent) fixed-term and 644 (94 per cent) subsidised respondents of the initial survey whose addresses were found in the population register. Among fixed-term employees the follow-up survey yielded 1,563 respondents (response rate 76 per cent) while 486 refused to participate. Among subsidised employees the corresponding figures were the 467 (response rate 73 per cent) and 177.

Crude figures suggested that loss from the cohorts was dependent on SOC, but the odds ratios showed the associations were statistically non-significant both among the fixed-term and in among subsidised employees (Tables 2 and 3). Among the fixed-term employees loss was least common in the oldest and among associate professionals; among subsidised employees no significant associations with the studied variables were seen.

Non-response at follow-up was associated with low SOC among the fixed-term employees (Table 2) but not among the subsidised employees (Table 3). In both cohorts, women and the oldest individuals were more likely to participate.

\section{Discussion}

This study examined sample attrition in cohorts of permanent and non-permanent employees. The focus was on the associations of baseline SOC with non-response to follow-up survey. In addition, we examined whether SOC predicted contact failure due to exit from the work place among permanent employees and contact failure due to unlocated address among fixed-term and subsidised employees. Corresponding associations with sociodemographic factors and self-rated health were also studied.

We found that low SOC predicted low response rate in the cohort of fixed-term employees. Contact failure was not related to SOC among permanent employees, i.e. those

Table 2: Characteristics of fixed-term employees who responded in the baseline and follow-up surveys and who did not respond in the follow-up survey, and odds ratios and $95 \%$ confidence intervals for response at follow-up by the characteristic.

\begin{tabular}{|c|c|c|c|c|c|c|}
\hline & \multirow{3}{*}{$\begin{array}{l}\text { Participants of baseline survey } \\
\qquad(\mathrm{n}=2194) \\
(\%)\end{array}$} & \multirow{3}{*}{$\begin{array}{l}\text { Respondents of follow-up } \\
\text { survey }(\mathrm{n}=1563) \\
(\%)\end{array}$} & \multicolumn{4}{|c|}{ Non-respondents to follow-up survey } \\
\hline & & & \multicolumn{2}{|r|}{$\operatorname{Lost}^{\mathrm{a}}(\mathrm{n}=145)$} & \multicolumn{2}{|c|}{ Refused $(n=486)$} \\
\hline & & & $(\%)$ & OR $(95 \% \mathrm{Cl})^{\mathrm{b}}$ & $(\%)$ & OR $(95 \% \mathrm{Cl})^{\mathrm{b}}$ \\
\hline \multicolumn{7}{|l|}{ Sense of coherence } \\
\hline High & 30 & 31 & 26 & 1 & 28 & 1 \\
\hline Intermediate & 49 & 50 & 46 & $1.02(0.66-1.57)$ & 48 & $0.93(0.72-1.21)$ \\
\hline Low & 21 & 19 & 28 & $0.68(0.41-1.14)$ & 24 & $0.69(0.50-0.94)$ \\
\hline \multicolumn{7}{|l|}{ Gender } \\
\hline Men & 18 & 16 & 17 & I & 25 & 1 \\
\hline Women & 82 & 84 & 83 & $1.02(0.63-1.66)$ & 75 & 1.68 (1.29-2.19) \\
\hline \multicolumn{7}{|l|}{ Age group } \\
\hline $17-29$ & 35 & 33 & 42 & 1 & 37 & 1 \\
\hline $30-49$ & 54 & 55 & 52 & $1.43(0.98-2.09)$ & 54 & $1.07(0.85-1.36)$ \\
\hline $50-64$ & II & 12 & 6 & 2.43 (1.16-5.09) & 9 & 1.52 (1.02-2.27) \\
\hline \multicolumn{7}{|l|}{ Occupational status } \\
\hline Professionals & 42 & 42 & 53 & 1 & 39 & 1 \\
\hline Associate professionals & 22 & 22 & 14 & $2.06(1.27-3.50)$ & 23 & $0.87(0.66-1.16)$ \\
\hline Clerks & 10 & 10 & 9 & $1.29(0.68-2.41)$ & 10 & $0.99(0.68-1.48)$ \\
\hline Manual workers & 26 & 26 & 24 & $1.40(0.89-2.17)$ & 28 & $0.82(0.62-1.07)$ \\
\hline \multicolumn{7}{|l|}{ Self-rated health } \\
\hline Good & 83 & 83 & 79 & 1 & 84 & 1 \\
\hline Poor & 17 & 17 & 21 & $0.75(0.47-1.19)$ & 16 & $1.20(0.88-1.63)$ \\
\hline
\end{tabular}

a Among fixed-term employees those whose addresses were not found in the population register

${ }^{b}$ Adjusted for age, sex, occupational status and baseline level of self-rated health 
Table 3: Characteristics of subsidised employees who responded in the baseline and follow-up surveys and who did not respond in the follow-up survey, odds ratios and $\mathbf{9 5 \%}$ confidence intervals for response at follow-up by characteristic.

\begin{tabular}{|c|c|c|c|c|c|c|}
\hline & \multirow{3}{*}{$\begin{array}{l}\text { Participants of baseline survey }(\mathrm{n} \\
=682) \\
(\%)\end{array}$} & \multirow{3}{*}{$\begin{array}{l}\text { Respondents of follow-up survey } \\
\qquad(\mathrm{n}=467) \\
(\%)\end{array}$} & \multicolumn{4}{|c|}{ Non-respondents to follow-up survey } \\
\hline & & & \multicolumn{2}{|r|}{$\operatorname{Lost}^{\mathrm{a}}(\mathrm{n}=38)$} & \multicolumn{2}{|c|}{ Refused $(n=177)$} \\
\hline & & & (\%) & OR $(95 \% \mathrm{Cl})^{\mathrm{b}}$ & $(\%)$ & OR $(95 \% \mathrm{Cl})^{\mathrm{b}}$ \\
\hline \multicolumn{7}{|l|}{ Sense of coherence } \\
\hline High & 20 & 21 & 16 & 1 & 20 & 1 \\
\hline Intermediate & 47 & 48 & 30 & $1.16(0.38-3.56)$ & 46 & $1.10(0.67-1.83)$ \\
\hline Low & 33 & 31 & 54 & $0.37(0.13-1.10)$ & 34 & $0.94(0.54-1.63)$ \\
\hline \multicolumn{7}{|l|}{ Gender } \\
\hline Men & 23 & 21 & 26 & 1 & 28 & 1 \\
\hline Women & 77 & 79 & 74 & $1.03(0.44-2.46)$ & 72 & $1.63(1.04-2.54)$ \\
\hline \multicolumn{7}{|l|}{ Age group } \\
\hline $17-29$ & 29 & 29 & 29 & 1 & 29 & 1 \\
\hline $30-49$ & 48 & 45 & 55 & $0.77(0.32-1.84)$ & 55 & $0.83(0.53-1.30)$ \\
\hline $50-64$ & 23 & 26 & 16 & $1.52(0.49-4.76)$ & 16 & $1.92(1.06-3.48)$ \\
\hline \multicolumn{7}{|l|}{ Occupational status } \\
\hline Professionals & 8 & 10 & 3 & I & 6 & 1 \\
\hline Associate professionals & 15 & 15 & 15 & $0.28(0.03-2.55)$ & 15 & $0.59(0.25-1.43)$ \\
\hline Clerks & 27 & 27 & 15 & $0.63(0.07-5.63)$ & 26 & $0.61(0.27-1.38)$ \\
\hline Manual workers & 50 & 48 & 67 & $0.23(0.29-1.77)$ & 53 & $0.55(0.25-1.20)$ \\
\hline \multicolumn{7}{|l|}{ Self-rated health } \\
\hline Good & 69 & 69 & 68 & I & 68 & 1 \\
\hline Poor & 31 & 31 & 32 & $1.27(0.54-2.97)$ & 32 & $0.99(0.64-1.54)$ \\
\hline
\end{tabular}

a Among subsidised employees those whose addresses were not found in the population register

${ }^{b}$ Adjusted for age, sex, occupational status and baseline level of self-rated health

who left work for "natural" reasons such as a move to another workplace, retirement or death, had only slightly lower SOC than the respondents. Among non-permanent employees contact failure tended to be more common in those with low SOC, but this association did not reach statistical significance.

According to Antonovsky [7,8] SOC predicts and explains an individual's movement along the health-disease continuum. He viewed SOC as individuals' global orientation or disposition leading to a certain attitude towards their internal and external environment [8]. A strong SOC means good resources to resist stressful encounters, including work-related stress and other exposures. In line with this, Feldt [16] found that employees with strong SOC had fewer psychosomatic symptoms and lower level of emotional exhaustion at work. Antonovsky's theory also suggests that SOC stabilises by the age of about 30, and the first years of employment are important in this development [8]. The period during which individuals leave their studies to enter the labour market appears particularly important [17]; if the early career is characterised by insecure entry into work, SOC may never reach the optimal level.
In our study, the permanent employees were older than the fixed-term and subsidised employees, and it is evident that majority of them should have had a stable SOC. However, as most of the non-permanent employees were older than 30, and we may assume that their SOC was also relatively stable.

Research in the field of psychiatry has documented that psychiatric disorders and psychopathology increase sample attrition due to loss of contact rather than refusal $[6,18]$. According to our results SOC does not follow this tendency. In other words it seems to be inappropriate to consider SOC simply as an indicator of mental morbidity or psychological well-being.

Poor self-rated health has been shown to predict sample attrition $[1,5,19]$. Our findings confirm this in the cohort of permanent employees, both with regard to nonresponse and to exit. In fixed-term employees the point estimate showed an opposite though statistically non-significant association with regard to non-response. On the other hand, among them responding was associated with high SOC. In all, these findings add one more paradox to the body of research concerning health and well-being of fixed-term employees [see e.g [20]]. 
Women tend to participate in follow-up more actively than men [19,21-23], although there are some conflicting findings $[2,24]$. In this study women also were more likely to respond in all cohorts. Several studies have explained this by pointing to gender differences in health. However, in our study such an explanation was unlikely because the analyses were adjusted for self-rated health at baseline.

The probability of responding is reported in most studies to increase with age $[7,10,12]$, although there are studies of elderly cohorts reporting opposite findings $[3,12]$. In our study the cohorts were relatively young. Thus, our finding of less attrition among older participants was to be expected.

Higher response rates have been reported among those with a higher socio-economic status [1-3,6,18,19,21-24]. This finding was replicated in our study but only among permanent employees.

This study, concentrating on associations between SOC and sample attrition during follow-up, does not permit conclusions of a potential SOC-related participation bias in the initial survey. It is possible that the effect of SOC is different in surveys conducted among unselected populations.

\section{Conclusion}

In the past, it was easier to follow up occupational cohorts throughout their working careers, as it was common for individuals to stay in one workplace. Nowadays such follow-up is difficult due to greater turnover in occupations and employers and employees. This study showed that it is possible to trace over 90 per cent of non-permanent employees by utilizing the Finnish Population Register. Inclusion of non-permanent employees, however requires, special arrangements, and among them sample attrition may be related to different factors than among permanent employees. Our finding of non-random sample attrition in relation to SOC serves as an example of factors which must be considered when following up occupational cohorts that include fixed-term employees.

\section{Abbreviations \\ SOC: Sense of Coherence.}

\section{Competing interests}

The author(s) declare that they have no competing interests.

\section{Authors' contributions}

VL carried out the statistical analyses and was responsible for writing the drafts of the manuscript. PV participated in designing the study and in the statistical analyses and contributed to the writing of the manuscript. JP was responsi- ble for production of the survey and register data and for the construction of the variables. MK and JV participated in designing the study and contributed to the writing of the manuscript. All authors read and approved the final manuscript.

\section{Acknowledgements}

This study was supported by the Academy of Finland (projects \#I I 7604 and \#105195), the Finnish Work Environment Foundation (projects \#101190 and \# 101295 ) and the participating town administrations.

\section{References}

I. Bauman A, Stiber J, Lowel H: Nonparticipation as a factor influencing the value of follow-up studies. Results of a telephone 5-year follow-up interview of 74-year-old participants of the Augsburg 1989/90 MONICA Survey. Gesundheitswesen 1997, 59(Suppl I): I9-25.

2. Goldberg M, Chastang F, Leclerc A, Zins M, Bonenfant S, Bugel I, Kaniewski N, Schmaus A, Niedhammer I, Piciotti M, Chevalier A, Godard C, Imbernon E: Socioeconomic, demographic, occupational, and health factors associated with participation in a long-term epidemiologic survey: a prospective study of the French GAZEL cohort and its target population. Am J Epidemiol 200I, I 54(4):373-384.

3. Van Beijsterveldt CE, van Boxtel MP, Bosma $H$, Houx PJ, Buntinx F, Jolles J: Predictors of attrition in a longitudinal cognitive aging study: the Maastricht Aging Study (MAAS). J Clin Epidemiol 2002, 55(3):216-223.

4. Caetano R, Ramisetty-Mikler S, McGrath C: Characteristics of non-respondents in a US national longitudinal survey on drinking and intimate partner violence. Addiction 2003, 98(6):791-797.

5. Drivsholm T, Falgaard Eplov L, Davidsen M, Jørgensen T, Ibsen H, Hollnagel $H$, Borch-Johnsen K: Representativeness in population-based studies: A detailed description of non-response in a Danish cohort study. Scand J Publ Health 2006, 34(6):623-63 I.

6. Badawi MA, Eaton WW, Myllyluoma J, Weimer LG, Gallo J: Psychopathology and attrition in the Baltimore ECA 15 -year followup 1981-1996. Soc Psychiatry Psychiatr Epidemiol 1999, 34(2):91-98.

7. Antonovsky A: Health, Stress and Coping San Francisco: Jossey-Bass; 1979.

8. Antonovsky A: Unraveling the Mystery of Health: How People Manage Stress and Stay Well San Francisco: Jossey- Bass; 1987.

9. Poppius E, Tenkanen L, Kalimo R, Heinsalmi P: The sense of coherence, occupation and the risk of coronary heart disease in the Helsinki Heart Study. Soc Sci Med 1999, 49:109-120.

10. Kivimäki M, Feldt T, Vahtera J, Nurmi J-E: Sense of coherence and health: Evidence from two cross-lagged longitudinal samples. Soc Sci Med 2000, 50:583-597.

II. Suominen S, Helenius H, Blomberg H, Uutela A, Koskenvuo M: Sense of coherence as a predictor of subjective state of health: results of 4 years of follow-up of adults. J Psychosomatic Res 2001, 50:77-86.

12. Surtees P, Wainwright N, Luben R, Khaw KT, Day N: Sense of coherence and mortality in men and in women in the EPIC. Norfolk United Kingdom prospective cohort study. Am J Epidemiol 2003, I 58( I 2): I202-I209.

13. Eriksson M, Lindström B: Antonovsky's sense of coherence scale and the relation with health: a systematic review. J Epidemiol Community Health 2006, 60:376-381.

14. Antonovsky A: The structure and properties of the sense of coherence scale. Soc Sci Med 1993, 36(6):725-733.

15. Classification of occupations, handbook no I4. In Statistics Finland Helsinki; 1997.

16. Feldt T: The role of sense of coherence in well-being at work: Analysis of main and moderator effects. Work Stress 1997, I I: I34- I 47

17. Virtanen $\mathrm{P}$, Liukkonen V, Vahtera J, Kivimäki M, Koskenvuo $M$ : Health inequalities in the workforce: the labour market core-periphery structure. Int J Epidemiol 2003, 32:1015-1021.

18. De Graaf R, Bijl RV, Smit F, Ravelli A, Vollebergh WA: Psychiatric and sociodemographic predictors of attrition in a longitudi- 
nal study: The Netherlands Mental Health Survey and Incidence Study (NEMESIS). Am J Epidemiol 2000, I 52(I I): 1039-1047.

19. Van Loon AJ, Tijhuis M, Picavet HS, Surtees PG, Ormel J: Survey non-response in the Netherlands: effects on prevalence estimates and associations. Ann Epidemiol 2003, I3(2): I05-II0.

20. Saloniemi A, Virtanen $P$, Vahtera J: The work environment in fixed-term jobs: are poor conditions inevitable? Work Employment Society 2004, 18:193-208.

21. Ronckers C, Land C, Hayes R, Verduijn P, van Leeuwen F: Factors impacting questionnaire response in a Dutch retrospective cohort study. Ann Epidemiol 2004, I 4(I):66-72.

22. Bucholz KK, Shayka JJ, Marion SL, Lewis CE, Pribor EF, Rubio DM: Is a history of alcohol problems or of psychiatric disorder associated with attrition at I I-year follow-up? Ann Epidemiol 1996, 6(3):228-234

23. Matthews FE, Chatfield M, Freeman C, McCracken C, Brayne C, MRC CFAS: Attrition and bias in the MRC cognitive function and ageing study: an epidemiological investigation. BMC Public Health 2004, 4: 12.

24. Pirzada A, Yan LL, Garside DB, Schiffer L, Dyer AR, Daviglus ML: Response rates to a questionnaire 26 years after baseline examination with minimal interim participant contact and baseline differences between respondents and nonrespondents. Am J Epidemiol 2004, I 59(I):94-101.

\section{Pre-publication history}

The pre-publication history for this paper can be accessed here:

http://www.biomedcentral.com/1471-2458/8/88/prepub

Publish with Bio Med Central and every scientist can read your work free of charge

"BioMed Central will be the most significant development for disseminating the results of biomedical research in our lifetime. "

Sir Paul Nurse, Cancer Research UK

Your research papers will be:

- available free of charge to the entire biomedical community

- peer reviewed and published immediately upon acceptance

- cited in PubMed and archived on PubMed Central

- yours - you keep the copyright 